\begin{tabular}{ll|l}
\cline { 2 - 3 } & \multicolumn{2}{l}{ Intervent Neurol 2012;1:143-150 } \\
\cline { 2 - 3 } & $\begin{array}{l}\text { DOI: 10.1159/000351687 } 2013 \text { S. Karger AG, Basel } \\
\text { Published online: July 2, 2013 }\end{array}$ & $\begin{array}{l}\text { (c) } \\
\text { 1664-9737/12/0014-0143 } \$ 38.00 / 0 \\
\text { www.karger.com/ine }\end{array}$ \\
\hline
\end{tabular}

\title{
Endovascular Treatment of Cervical Artery Dissection: Ten Case Reports and Review of the Literature
}

\author{
Frank Ahlhelm ${ }^{a} \quad$ Robyn Melanie Benz ${ }^{a} \quad$ Stephan Ulmer ${ }^{a} \quad$ Philippe Lyrer $^{b}$ \\ Christoph Stippich $^{a}$ Stefan Engelter ${ }^{b}$ \\ a Division of Diagnostic and Interventional Neuroradiology, Department of Radiology, and \\ ${ }^{b}$ Department of Neurology, University of Basel Hospital, Basel, Switzerland
}

\author{
Key Words \\ Cervical artery dissection $\cdot$ Endovascular treatment $\cdot$ Stenting $\cdot$ Stroke
}

\begin{abstract}
Purpose: The role of endovascular treatment in cases of cervical artery dissection (CeAD) is debatable. With an increasing number of endovascular therapies such as endovascular recanalization and embolization the number of complications such as iatrogenic dissection is also rising. We report our experience with endovascular stenting in the treatment of patients presenting with CeAD. Methods: We included all consecutive patients with CeAD $(n=168)$ treated in our hospital between 2001 and 2010 for our retrospective study. Patients with CeAD were considered eligible for stenting: (1) in iatrogenic dissections and (2) in noniatrogenic dissections if they suffered from recurrent ischemic events despite antithrombotic treatment. Results: During our observation period 10 out of 168 patients presenting with CeAD were selected for stenting. Several types of stents were used. Stenting was technically successful in 8 but unsuccessful in 2 patients with complete arterial occlusion. Stent-related clinically apparent complications occurred in 3 of the 10 patients. All were transient. During a mean follow-up of $47( \pm 24.8)$ months none of the patients had new cerebrovascular ischemic events. Conclusion: In our patient sample stenting due to dissection is a rare procedure performed in less than $10 \%$ of CAD patients. It should be considered as a feasible rescue treatment in cases of impending stroke despite optimal antithrombotic therapy.
\end{abstract}




\section{Introduction}

Cervical artery dissection (CeAD) is an important cause of stroke in patients younger than 45 years [1-5].

CeAD can be defined as separation between the inner and medial layer of the artery wall that splits into a longitudinal fashion leading to mural hemorrhage. Mural hemorrhage can occur secondary to an intimal tear or by rupture of vasa vasorum [6].

Dissections used to be diagnosed by angiography [7-10]. Nowadays, noninvasive techniques, especially MR imaging, serve to confirm the diagnosis and in particular to visualize mural hematoma in the wall of the dissected artery.

It is still debated whether, in CeAD patients, anticoagulation or antiplatelet agents are superior, balancing the risk and benefits of either approach [11-13]. Anticoagulation is widely advocated and often used [7, 14-16]. However, this treatment is not based on randomized controlled studies $[17,18]$. Endovascular therapy of CAD has been shown to be feasible in small series $[19,20]$. Stents have proven to provide the necessary centrifugal force to enable apposition of the dissected segment to the vessel wall and thereby to obliterate the false lumen and resolve the stenosis. The current ASA/AHA guidelines 2011 recommend antithrombotic treatment for patients with ischemic stroke or TIA and CeAD. Stenting should only be considered in patients with recurrent cerebral ischemic events despite optimal antithrombotic therapy [21].

The main issue of an endovascular approach in the treatment of CeAD is an appropriate selection of patients who will benefit from this invasive procedure.

\section{Materials and Methods}

\section{Patient Population}

We retrospectively searched: (1) the local CeAD database for all patients with CeAD and (2) the neuroradiological database for all CeAD patients who underwent stenting for CeAD between January 2001 und September 2010 in our hospital.

The diagnosis of CeAD was based on widely accepted diagnostic criteria [22, 23]. Briefly, CAD patients had to present mural hematoma, long tapering stenosis, intimal flap, double lumen or occlusion $>2 \mathrm{~cm}$ above the carotid bifurcation.

Patients were eligible for the current study: (1) if they had an iatrogenic CeAD or (2) if they had recurrent ischemic events (stroke, TIA) despite optimal antithrombotic treatment according to the treating physicians.

Informed consent for diagnostic angiography and stent implantation was obtained from all patients or medical guardians with the exception of emergency cases.

\section{Stenting}

Patients were admitted to the stroke unit. They received dual antiplatelet therapy with clopidogrel (loading dosage $300 \mathrm{mg}$ followed by $75 \mathrm{mg}$ for 6 weeks) and ASS (loading dosage $500 \mathrm{mg}$ followed by $100 \mathrm{mg}$ per day). Intravenous heparin was given as bolus of $60 \mathrm{IU} / \mathrm{kg}$ (max. $5000 \mathrm{IU}$ ) followed by a $20-\mathrm{IU} / \mathrm{kg} / \mathrm{h}$ heparin infusion) to achieve an activated clotting time of about $250 \mathrm{~s}$ and stopped $12 \mathrm{~h}$ later if no in-stent thrombosis was detected on neurosonography. Thereafter intravenous heparin was replaced by subcutaneous nadroparin calcium (Clexane ${ }^{\circledR}$; Aventis Pharma, Germany), which was administered at a dose of $0.4 \mathrm{ml}$ every $24 \mathrm{~h}$ until discharge.

The technical aspect of stenting has been described earlier.

In cases of carotid artery stenting, we used self-expanding stents (Wallstent ${ }^{\circledR}$, Boston Scientific and Astron Pulsar ${ }^{\circledR}$, Biotronik), whereas for stenting of vertebral artery dissection self-expanding (Astron Pulsar, Biotronik, as well as premounted balloon-expandable stents (Guidant Multilink Vision ${ }^{\circledR}$, Guidant; Tsunami ${ }^{\circledR}$, Terumo, and WaveMax ${ }^{\circledR}$, Jondi AB) were used (table 1).

Follow-up consisted of imaging using neurosonography, magnetic resonance imaging (MRI, including MR angiography, i.e. time-of-flight imaging for the intracranial arteries and contrast-enhanced MR angiography of the cervical arteries) and/or computed tomography (CT, with CT angiography) as well as clinical examinations. 
Ahlhelm et al.: Endovascular Treatment of Cervical Artery Dissection: Ten Case Reports and Review of the Literature

Table 1. Characteristics of CAD patients undergoing endovascular treatment

\begin{tabular}{|c|c|c|c|c|c|c|c|c|c|c|}
\hline $\begin{array}{l}\mathrm{Pa}- \\
\text { tient }\end{array}$ & $\begin{array}{l}\text { Age } \\
\text { years }\end{array}$ & Vessel & $\begin{array}{l}\text { Pseudo- } \\
\text { aneu- } \\
\text { rysm }\end{array}$ & $\begin{array}{l}\text { Etiology of } \\
\text { dissection }\end{array}$ & $\begin{array}{l}\text { Grade of stenosis } \\
\text { pre-/postintervention }\end{array}$ & Stent (mm) & $\begin{array}{l}\text { Complications } \\
\text { (procedural) }\end{array}$ & $\begin{array}{l}\text { Clinical } \\
\text { residues/ } \\
\text { neurologic } \\
\text { deficits due } \\
\text { to stenting }\end{array}$ & $\begin{array}{l}\text { Periprocedural } \\
\text { imaging } \\
\text { (findings) }\end{array}$ & $\begin{array}{l}\text { Imaging follow-up } \\
\text { (months postpro- } \\
\text { cedure) }\end{array}$ \\
\hline 1 & 47 & $\begin{array}{l}\text { left } \\
\text { VA }\end{array}$ & no & iatrogenic & $\begin{array}{l}\text { complete occlusion/ } \\
\text { complete } \\
\text { recanalization }\end{array}$ & Pulsar 6/60 & no & no & $\begin{array}{l}\text { duplex sonography } \\
\text { (normal flow) }\end{array}$ & $\begin{array}{l}\text { MRI }(12,15) \\
\text { no remaining } \\
\text { lesions, } \\
\text { normal flow }\end{array}$ \\
\hline 2 & 59 & $\begin{array}{l}\text { left } \\
\text { ICA }\end{array}$ & no & $\begin{array}{l}\text { sponta- } \\
\text { neous }^{1}\end{array}$ & $\begin{array}{l}\text { subtotal occlusion } \\
\text { (>95\%)/complete } \\
\text { recanalization }\end{array}$ & Wallstent 9/30 & no & no & $\begin{array}{l}\text { duplex sonography } \\
\text { (normal flow) }\end{array}$ & $\begin{array}{l}\text { MRI (15) } \\
\text { preexisting lesion } \\
\text { left frontal lobe, } \\
\text { normal flow }\end{array}$ \\
\hline 3 & 67 & $\begin{array}{l}\text { left } \\
\text { ICA }\end{array}$ & no & $\begin{array}{l}\text { sponta- } \\
\text { neous }^{1}\end{array}$ & $\begin{array}{l}\text { subtotal occlusion } \\
\text { (>95\%)/complete } \\
\text { recanalization }\end{array}$ & Wallstent 9/30 & no & no & $\begin{array}{l}\text { MRI (chronic ischemic } \\
\text { lesions) } \\
\text { duplex sonography } \\
\text { (normal flow) }\end{array}$ & $\begin{array}{l}\text { duplex sonography } \\
(6,12,24,36) \\
\text { normal flow }\end{array}$ \\
\hline 4 & 71 & $\begin{array}{l}\text { left } \\
\text { VA }\end{array}$ & no & iatrogenic & $\begin{array}{l}\text { subtotal occlusion } \\
(>95 \%) / \text { complete } \\
\text { recanalization }\end{array}$ & $\begin{array}{l}2 \times \text { Multilink } \\
\text { Vision } 4 / 23 \\
1 \times \text { WaveMax } 6 / 38\end{array}$ & $\begin{array}{l}\text { thrombosis of } \\
\text { basilar artery - } \\
\text { successful } \\
\text { thrombolysis }\end{array}$ & no & $\begin{array}{l}\text { MRI (multiple small } \\
\text { embolic lesions ) } \\
\text { duplex sonography } \\
\text { (normal flow) }\end{array}$ & $\begin{array}{l}\text { Duplex } \\
\text { Sonography }(24, \\
48,60,72) \\
\text { normal flow }\end{array}$ \\
\hline 5 & 58 & $\begin{array}{l}\text { left } \\
\text { ICA }\end{array}$ & yes & $\begin{array}{l}\text { sponta- } \\
\text { neous }\end{array}$ & $\begin{array}{l}\text { high-grade } \\
\text { stenosis }(70 \%) / \\
\text { complete } \\
\text { recanalization }\end{array}$ & $\begin{array}{l}2 \times \text { Wallstent } 7 / 30 \text {, } \\
9 / 30 \text { and balloon } \\
\text { dilatation with } \\
\text { Gazelle } 4 / 20\end{array}$ & dysphagia & no & $\begin{array}{l}\text { MRI (no lesions) } \\
\text { duplex sonography } \\
\text { (normal flow) }\end{array}$ & $\begin{array}{l}\text { duplex sonography } \\
(24,48,60) \\
\text { normal flow }\end{array}$ \\
\hline 6 & 47 & $\begin{array}{l}\text { left } \\
\text { ICA }\end{array}$ & no & traumatic $^{1}$ & $\begin{array}{l}\text { complete } \\
\text { occlusion }\end{array}$ & $\begin{array}{l}\text { technically } \\
\text { not feasible }\end{array}$ & no & no & $\begin{array}{l}\text { duplex sonography } \\
\text { (occlusion of the } \\
\text { ICA, normal flow } \\
\text { ACA and MCA) }\end{array}$ & $\begin{array}{l}\text { duplex sonography } \\
(6,33,60) \\
\text { occlusion of the } \\
\text { ICA, normal flow in } \\
\text { ACA and MCA }\end{array}$ \\
\hline 7 & 27 & $\begin{array}{l}\text { right } \\
\text { VA }\end{array}$ & no & iatrogenic & $\begin{array}{l}\text { complete occlusion/ } \\
\text { complete } \\
\text { recanalization of the } \\
\text { vertebral artery }\end{array}$ & $\begin{array}{l}3 \text { coronary stents } \\
3.5 / 15\end{array}$ & $\begin{array}{l}\text { patient died from } \\
\text { unsuccessful lysis } \\
\text { of preexisting } \\
\text { thrombus of the } \\
\text { basilar artery }\end{array}$ & - & - & - \\
\hline 8 & 68 & $\begin{array}{l}\text { left } \\
\text { ICA }\end{array}$ & no & iatrogenic & $\begin{array}{l}\text { high grade stenosis } \\
(70 \%) / \text { complete } \\
\text { recanalization }\end{array}$ & Pulsar 6/40 & $\begin{array}{l}\text { facial nerve } \\
\text { paresis }\end{array}$ & no & $\begin{array}{l}\text { MRI (multiple small } \\
\text { embolic lesions) } \\
\text { duplex sonography } \\
\text { (normal flow) }\end{array}$ & not available \\
\hline 9 & 49 & $\begin{array}{l}\text { right } \\
\text { ICA }\end{array}$ & no & iatrogenic & $\begin{array}{l}\text { subtotal occlusion } \\
(>95 \%) / \text { complete } \\
\text { recanalization }\end{array}$ & Wallstent 9/40 & no & no & $\begin{array}{l}\text { MRI (multiple small } \\
\text { embolic lesions ) } \\
\text { duplex sonography } \\
\text { (normal flow) }\end{array}$ & $\begin{array}{l}\text { MRI }(12) \\
\text { duplex sonography } \\
(6,12) \\
\text { normal flow }\end{array}$ \\
\hline 10 & 53 & $\begin{array}{l}\text { right } \\
\text { ICA }\end{array}$ & no & $\begin{array}{l}\text { sponta- } \\
\text { neous }{ }^{1}\end{array}$ & $\begin{array}{l}\text { complete } \\
\text { occlusion }\end{array}$ & $\begin{array}{l}\text { technically } \\
\text { not feasible }\end{array}$ & no & no & $\begin{array}{l}\text { MRI (vessel occlusion, } \\
\text { subacute ischemic } \\
\text { lesions) }\end{array}$ & $\begin{array}{l}\text { CT (4) } \\
\text { brain defects (ACA } \\
\text { and MCA territory) }\end{array}$ \\
\hline
\end{tabular}

VA = Vertebral artery; ICA = internal carotid artery; ACA = anterior cerebral artery; MCA = middle cerebral artery.

1 Indication for treatment was hemodynamically relevant stenosis with imminent hemodynamic infarctions.

2 Indication for treatment was recurrent cerebral ischemia despite optimal antithrombotic treatment; iatrogenic dissection happened during endovascular therapeutic maneuvers.

\section{Results}

\section{Study Population}

From 1999 till 2010 a total of 168 patients ( 67 women, 101 men) were diagnosed with CeAD; 10 out of the 168 patients ( 4 women, 6 men; mean age $54.6 \pm 13.1$ years) were treated with stenting. Baseline patient characteristics are summarized in table 1. Indications were hemodynamically relevant stenosis with imminent hemodynamic infarctions ( $n=4)$, recurrent cerebral ischemia despite optimal antithrombotic treatment $(n=1)$ and iatrogenic 
Fig. 1. Stenting of the left internal carotid artery because of an iatrogenic dissection (thick arrows) during distal access maneuver for endovascular treatment of an intracranial cavernous internal carotid artery aneurysm (thin arrows). Selective angiography of the left internal carotid artery. Digital subtraction angiography $(\mathbf{a}-\mathbf{c})$ and fluoroscopy (d) before (a, b) and after stenting (c, d) in posterior-anterior $(\mathbf{a}, \mathbf{c})$ and lateral projections (b, d), revealing circumscribed dissection of the cervical segment of the left internal carotid artery. Distal access was necessary to treat an intracranial internal carotid artery aneurysm (thin arrow). The carotid stent which was used for stenting is rather radiolucent and hard to depict. The ends of the stent are marked by two dotted lines $(\mathbf{c}, \mathbf{d})$.
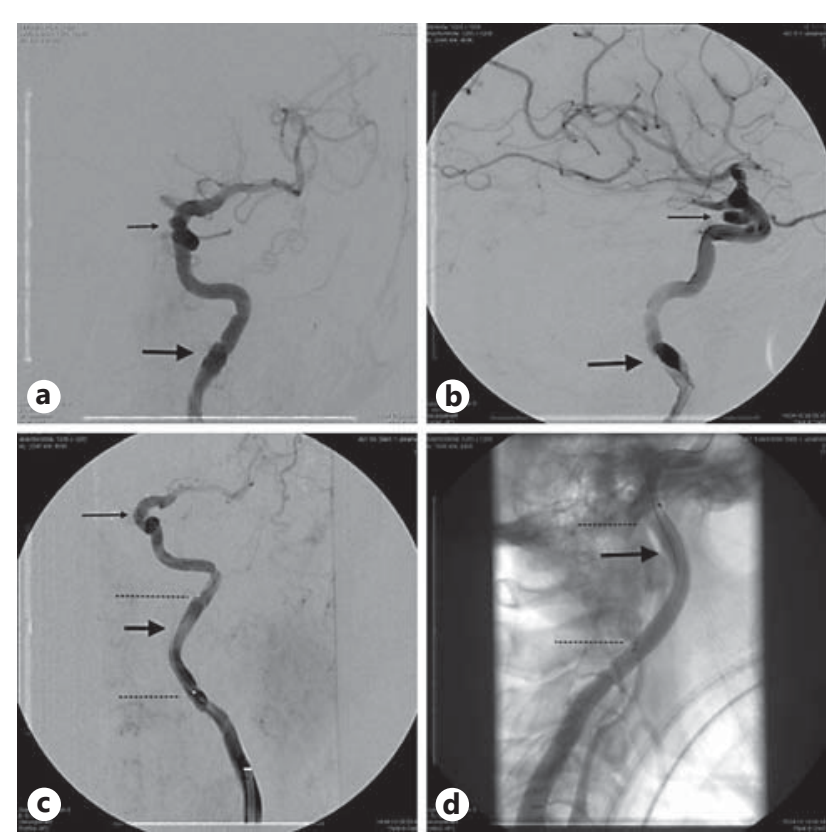

Ahlhelm et al.: Endovascular Treatment of Cervical Artery Dissection: Ten Case Reports and Review of the Literature

dissection $(n=5)$ during endovascular therapeutic maneuvers such as aneurysm embolization, as illustrated in figure 1.

Of the 10 patients, 7 had CAD of cervical internal carotid artery ( 2 of them were partially intracranial); 3 patients had vertebral artery dissection (table 1).

Three of the iatrogenic and all vertebral artery dissections occurred during endovascular therapeutic maneuvers (one during coiling of a basilar tip aneurysm, one during stenting of a subtotal stenosis of basilar artery and one during lysis of a thrombus of the basilar artery). One of the iatrogenic internal carotid artery dissections occurred during coiling of an intracranial internal carotid artery aneurysm (fig. 1) and the other occurred after thrombendarterectomy of the right internal carotid artery. Even though 1 patient presented with multiple aneurysms, none of the patients with spontaneous dissections fulfilled the criteria for fibromuscular dysplasia. Additional pseudoaneurysms were found in only 1 patient.

Of the 10 patients, 4 had subtotal occlusion ( $\geq 90 \%$ lumen narrowing according to NASCET; pseudoocclusion), 4 had complete occlusion of the vessel and 2 had high-grade stenosis (i.e. about 70\% lumen narrowing according to NACSET) of the dissected vessel segment. Stenting was feasible in 8 patients. All 3 patients with vertebral artery dissections (all iatrogenic) were stented successfully; 1 patient had complete occlusion and 2 had subtotal occlusions; 5 of the patients with dissection of the cervical internal carotid artery could be treated successfully. In 2 patients (patients 6 and 10; table 1) stenting was not feasible due complete occlusion of the vessel and therefore failure to enter the true lumen with the catheter. One of those patients recovered without any neurological sequelae and neurosonography showed sufficient collateral flow of the ipsilateral anterior and middle cerebral artery via the anterior communicating artery. The other patient (patient 10) showed large brain defects of the anterior and middle cerebral artery territory on MR imaging.

For treatment of the patients with vertebral artery dissections four different stents were used; 1 patient was treated with a nitinol shape memory alloy self-expanding stent (Astron Pulsar; Biotronik), 1 with three premounted balloon-expandable cobalt chromium stents (2 Multilink Vision, Guidant and 1 WaveMax, Jondi AB) and the 3rd was treated with three balloon-expandable coronary stents (Tsunami; Terumo). 
The internal carotid artery dissections were treated with two different stents. Except for 1 patient who received a nitinol shape memory alloy self-expanding stent (Astron Pulsar; Biotronik), all the other cases were treated using a self-expanding stainless steel stent (Wallstent; Boston Scientific) deployed in different sizes (table 1). Only 1 patient required additional balloon dilation after stent deployment.

One patient with successfully stented iatrogenic dissection of the vertebral artery was lost for follow-up, dying of unsuccessfully treated preexisting thrombotic basilar artery occlusion. All other 9 patients, including the patients not being stented, received duplex sonography for periprocedural (within 30 days after intervention) follow-up; 6 had additional imaging with MRI, including time-of-flight MRA and contrast-enhanced MRA.

Four patients suffered from periprocedural complications. These included transient dysphagia $(n=1)$ without ischemic lesions in postprocedural MRI scans, transient facial nerve paresis $(\mathrm{n}=1)$ with multiple ischemic lesions in diffusion-weighted MRI, and thrombosis of the basilar artery $(\mathrm{n}=1)$, which was treated successfully by thrombolysis with 600,000 IU urokinase. The postinterventional MRI showed clinically silent small embolic lesions in the cerebellum and in the territory of the posterior cerebral artery. Another patient showed small embolic lesions in postprocedural MRI, but also without clinical symptoms.

During a mean follow-up of $47( \pm 24.8)$ months, none of the successfully stented patients had additional transient attacks or stroke. All successfully treated patients underwent duplex sonography after 6 months and every year, up to a maximum of 7 years in 1 case (table 1). For 3 patients additional follow-up imaging using MRI technique was available showing no new structural defects.

\section{Discussion}

In $\mathrm{CeAD}$ about $90 \%$ of the stenoses resolve and about two thirds of the occlusions recanalize $[24,25]$. Thus, it is not surprising that just 10 of our 168 patients had stenting.

CeAD may show a progression of the hemodynamic compromise resulting in progressive or complete stroke, in particular within 5 days after dissection onset, emphasizing the importance of strict monitoring and best medical treatment [26]. Concerning that point, however, it is still not evident if anticoagulation is superior to antiplatelet treatment [16, 27]. Because of high mortality and morbidity rates, indications for surgical treatment such as endarterectomy, thrombectomy, extracranial-intracranial bypass or vessel graft placement is given only in very rare cases for the treatment of CeAD with complete vessel occlusion $[9,18]$. In the past, surgery was performed as either bypass or even ligation as ultima ratio because carotid endarterectomy is generally not recommended. Surgical treatment is difficult and sometimes not possible because of the longer length and generally more distal extent compared with atherosclerotic lesions, and therefore cranial nerves are especially threatened by an open surgical approach. With refinements of catheter devices and improvement in technologies of implantation such as endovascular stents, interventional treatment has gained more and more importance, especially in patients remaining symptomatic by recurrent strokes despite medication. Interventional treatment options consist of stenting with or without additional balloon angioplasty at the level of the dissection, whereas endovascular embolization and thereby occlusion of the dissected vessel by coiling is nowadays generally not necessary. The most critical step of stenting in CeAD is to enter the true lumen by a microguidewire and thus the selective microcatheterization of the normal vessel lumen distally to the dissection.

It is important that the stent strut covers the whole dissected segment to assure the apposition of the dissected segment to the vessel wall, obliterating the false lumen and recon- 
structing the vessel lumen, thereby limiting the occurrence of emboli and resolving the stenosis [28].

With increasing numbers of endovascular procedures, procedure-related complications such as dissection are also expected to rise in the future.

Stenting was not feasible in 2 patients with complete occlusion of the dissected vessel. This means a technical success rate of $80 \%$ which is a bit lower compared with other series or reviews of the literature with an average success rate of $>90 \%$ [20]. One explanation might be the high amount of total or nearby occlusion in our patient sample (80\%). The critical point of the procedure is to enter the true lumen with the microguidewire, which is facilitated in the case of residual perfusion compared with complete occlusion.

Two patients suffered from transient focal neurological deficits in the postoperative course. Of these, 1 presented with dysphagia most likely caused by intubation due to its complete resolving within $24 \mathrm{~h}$ after stenting and no evident morphological correlation in diffusion-weighted MRI. The other patient suffered from transient paresis of the facial nerve, but also without correlation in diffusion-weighted MRI. Another patient showing new embolic infarctions on MRI had no neurological deficits, i.e. subclinical ischemic lesions. However, these patients could be discharged without any neurological deficits. Therefore, we agree with other authors claiming the treatment to be an appropriate and effective approach in selected patients [19,20,29].

Since medical treatment is successful in the majority of cases, endovascular treatment, i.e. stenting, is not considered to be the method of choice in every case of CAD, which explains the relatively low number of procedures performed in our institution. However, it has already shown its potency in the case of treatment failures using only medical treatment [30].

These recommendations are widely represented in the current ASA/AHA guidelines 2011, proposing consideration of endovascular treatment for patients with stroke or TIA and extracranial carotid or vertebral arterial dissection in cases of definite recurrent cerebral ischemic events [21]. However, there is currently no recognized consensus among both neurologists and neuroradiologists of a preferred time point for stenting or even the type of stent device used. In this study we used both self-expansive and balloon-expandable stents. On the one hand, the stent should have sufficient self-expanding forces, which may help to avoid additional balloon angioplasty after stenting, and on the other hand, a low metal-tovessel ratio is required to reduce the risk of in-stent stenosis. New highly flexible selfexpanding stents especially designed for intracranial use seem to be promising also for endovascular treatment in cases of CeAD. Concerning iatrogenic dissection during endovascular maneuvers, practice patterns for indications to stent a dissected vessel segment are highly variable and often institution specific.

A limitation of our retrospective study is that only 10 patients could be included. Therefore, no statistical analysis was possible.

\section{Conclusion}

A review of the literature, informal collation of data and previous meta-analyses suggest that endovascular treatment is a good treatment option in CeAD, especially in cases of recurrent ischemic events despite medical treatment.

Nevertheless, stenting in cases of CeAD is a very rare procedure performed in less than $10 \%$ of our patients within the last 10 years. 
Ahlhelm et al.: Endovascular Treatment of Cervical Artery Dissection: Ten Case Reports and Review of the Literature

\section{Disclosure Statement}

The authors declare that they have no conflict of interest. Drug dosage: the authors and the publisher have exerted every effort to ensure that drug selection and dosage set forth in this text are in accord with current recommendations and practice at the time of publication. However, in view of ongoing research, changes in government regulations, and the constant flow of information relating to drug therapy and drug reactions, the reader is urged to check the package insert for each drug for any changes in indications and dosage and for added warnings and precautions. This is particularly important when the recommended agent is a new and/or infrequently employed drug.

\section{References}

- 1 Schulte S, Donas KP, Pitoulias GA, Horsch S: Endovascular treatment of iatrogenic and traumatic carotid artery dissection. Cardiovasc Intervent Radiol 2008;31:870-874.

- 2 Ehrenfeid WK, Wylie EJ: Spontaneous dissection of the internal carotid artery. Arch Surg 1976;111:12941301.

3 Bogousslavsky J, Despland P-A, Regli F: Spontaneous carotid artery dissection with acute stroke. Arch Neurol 1987;44:137-140.

4 Leys D, Moulin TH, Stoikovic T, Begey S, et al: Follow-up of patients with history of cervical artery dissection. Cerebrovasc Dis 1995;5:43-49.

5 Leys D, Bandu L, Henon H, et al: Clinical outcome in 287 consecutive young adults (15 to 45 years) with ischemic stroke. Neurology 2002;59:26-33.

6 Anson J, Crowell AM: Cervicocranial arterial dissection. Neurosurgery 1991;29:89-96.

7 Hart AG, Easton JD: Dissections of cervical and cerebral arteries. Neurol Clin 1983;1:255-282.

- 8 Mokri B, Houser OW, Sandok BA, Piepgras DG: Spontaneous dissections of the vertebral arteries. Neurology 1988;38:880-885.

- 9 Schievink WI, Mokri B, O’Fallon WM: Recurrent spontaneous cervical artery dissection. N Engl J Med 1994; 330:393-397.

10 Schievink WI, Mokri B, Piepgras DG: Spontaneous dissections of cervicocephalic arteries in childhood and adolescence. Neurology 1994;44:1607-1612.

11 Lyrer P, Engelter S: Antithrombotic drugs for carotid artery dissection. Stroke 2004;35:613-614.

12 Lyrer PA: Extracranial arterial dissection: anticoagulation is the treatment of choice: against. Stroke 2005;36: 2042-2043.

13 Norris JW: Extracranial arterial dissection: anticoagulation is the treatment of choice: for. Stroke 2005;36: 2041-2042.

14 Cimini N, D’Andrea P, Gentile M, et al: Cervical artery dissection: a 5-year prospective study in the Belluno district. Eur Neurol 2004;52:207-210.

15 Menon RK, Markus HS, Norris JW: Results of a UK questionnaire of diagnosis and treatment in cervical artery dissection. J Neurol Neurosurg Psychiatry 2008;79:1122-1127.

16 Beletsky V, Nadareishvili Z, Lynch J, et al, Canadian Stroke Consortium: Cervical arterial dissection: time for a therapeutic trial? Stroke. 2003;34:2856-2860.

17 Leys D, Lucas Ch, Gobert M, et al: Cervical artery dissections. Eur Neurol 1997;37:3-12.

18 Schievink WJ: Spontaneous dissection of the carotid and vertebral arteries. N Engl J Med 2001;344:898-906.

19 Kadkhodayan Y, Jeck DT, Moran CJ, Derdeyn CP, Cross DT 3rd: Angioplasty and stenting in carotid dissection with or without associated pseudoaneurysm. AJNR 2005;26:2328-2335.

-20 Pham M, Rahme R, Arnaout O, Hurley M, Bernstein RA, Batjer HH, Bendok BR: Endovascular stenting of extracranial carotid and vertebral artery dissections : a systematic review of the literature. Neurosurgery 2011;68: 856-866.

21 Writing Committee Members, Brott TG, Halperin JL, Abbara S, Bacharach JM, Barr JD, Bush RL, Cates CU, Creager MA, Fowler SB, Friday G, Hertzberg VS, McIff EB, Moore WS, Panagos PD, Riles TS, Rosenwasser RH, Taylor AJ, Jacobs AK, Smith SC Jr: ASA/ACCF/AHA/AANN/AANS/ACR/ASNR/CNS/SAIP/SCAI/SIR/SNIS/ SVM/SVS guideline on the management of patients with extracranial carotid and vertebral artery disease: executive summary: a report of the American College of Cardiology Foundation/American Heart Association Task Force on practice guidelines, and the American Stroke Association, American Association of Neuroscience Nurses, American Association of Neurological Surgeons, American College of Radiology, American Society of Neuroradiology, Congress of Neurological Surgeons, Society of Atherosclerosis Imaging and Prevention, Society for Cardiovascular Angiography and Interventions, Society of Interventional Radiology, Society of Neurointerventional Surgery, Society for Vascular Medicine, and Society for Vascular Surgery. Stroke 2011;42:e420- e463.

22 Arnold M, Nedeltchev K, Sturzenegger M, et al: Thrombolysis in patients with acute stroke caused by cervical artery dissection: analysis of 9 patients and review of the literature. Arch Neurol 2002;59:549-553. 
Ahlhelm et al.: Endovascular Treatment of Cervical Artery Dissection: Ten Case Reports and Review of the Literature

23 Engelter ST, Rutgers MP, Hatz F, et al: Intravenous thrombolysis in stroke attributable to cervical artery dissection. Stroke 2009;40:3772-3776.

24 Guillon B, Lévy C, Bousser MG: Internal carotid artery dissection: an update. J Neurol Sci 1998;153:146-158.

-25 Djouhri H, Guillon B, Brunereau L, et al: MR angiography for the long-term follow-up of dissecting aneurysms of the extracranial internal carotid artery. AJR Am J Roentgenol 2000;174:1137-1140.

26 Biousse V, D’Anglejan-Chatillon J, Touboul PJ, Amarenco P, Bousser MG: Time course of symptoms in extracranial carotid artery dissections. A series of 80 patients. Stroke 1995;26:235-239.

27 Lyrer P, Engelter S: Antithrombotic drugs for carotid artery dissection. Cochrane Database Syst Rev 2010; 10:CD000255.

28 Lylyk P, Cohen JE, Ceratto R, et al: Angioplasty and stent placement in intracranial atherosclerotic stenoses and dissections. AJNR Am J Neuroradiol 2002;23:430-436.

29 Goyal MS, Derdeyn CP: The diagnosis and management of supraaortic arterial dissections. Curr Opin Neurol 2009;22:80-89.

30 Cohen JE, Gomori JM, Umansky F: Endovascular management of spontaneous bilateral symptomatic vertebral artery dissections. AJNR Am J Neuroradiol 2003;24:2052-2056. 